\title{
A Computational Aerodynamics Simulation of the NREL Phase II Rotor
}

\author{
N.S. Tachos ${ }^{*}, 1$, A.E. Filios ${ }^{*}, 2$, D.P. Margaris ${ }^{1}$ and J.K. Kaldellis ${ }^{3}$ \\ ${ }^{1}$ Fluid Mechanics Laboratory, Mechanical Engineering and Aeronautics Department, University of Patras, GR-265 04 \\ Patras, Greece \\ ${ }^{2}$ Fluid Mechanics and Turbomachinery Laboratory, Department of Mechanical Engineering Educators, School of \\ Pedagogical and Technological Education, Athens, Greece \\ ${ }^{3}$ Laboratory of Soft Energy Applications and Environmental Protection, Mechanical Engineering Department, \\ Technical Education Institute of Piraeus, P.O. Box 41046, Athens 12201, Greece
}

\begin{abstract}
The work presented in this article aims to the calculation of the aerodynamic characteristics of the NREL phase II rotor that is a horizontal axis downwind wind turbine rotor and which is assumed to stand isolated in the space. The Reynolds averaged Navier-Stokes equations combined with the Spalart-Allmaras turbulence model that describes the three dimensional steady state flow about the wind turbine rotor are solved with the aid of a commercial CFD code. A structured grid of approximately 3.3 million cells formulates the computational domain. The numerical results for the considered wind turbine rotor are benchmarked against wind tunnel measurements obtained at free stream velocity of $7.2 \mathrm{~m} / \mathrm{s}$ in the framework of VISCEL project. The comparisons show that the used CFD code can accurately predict the span-wise loading of the wind turbine rotor.
\end{abstract}

Keywords: Wind turbine, NREL phase II rotor, VISCEL project, CFD.

\section{INTRODUCTION}

With the experience of "oil shock" in the early 1970s and the environmental impact of burning fuels, energy policy has confirmed the improvement of the environmental sustainability of energy as a primary objective and the use of renewable sources [1]. Wind power generation is an environmental friendly method of generating electric energy through the operation of a generator attached to the axis of a rotor blade that turns due to the rotational action of the resultant aerodynamic force generated by the change of wind momentum. Since wind energy is a low-density source of power, it is important to maximize the efficiency of wind machines. The prediction of the aerodynamic properties of wind turbines is more challenging in many ways than that of already complicated problems such us helicopter rotors and propellers.

The design of a wind turbine rotor requires accurate, reliable and robust numerical predictions. The literature reports various methods that compare numerical predictions to experiments. The methods vary from blade element momentum (BEM) theory [2], vortex lattice [3], coupled viscous/potential panel [4] to variants of Reynolds averaged Navier-Stokes (N-S) [5, 6]. The computer related requi-

*Address correspondence to these authors at the Fluid Mechanics Laboratory, Mechanical Engineering and Aeronautics Department, University of Patras, GR-265 04 Patras, Greece; Tel. and Fax: +30 2610997202, E-mail: taxos@mech.upatras.gr

Fluid Mechanics and Turbomachinery Laboratory, Department of Mechanical Engineering Educators, School of Pedagogical and Technological Education, Athens, Greece; E-mail: fmtulab1@otenet.gr rements which set in full N-S simulations [7-9] are overcome with hybrid N-S solver/free wake method. In this method, the computational domain is divided in N-S regions near the rotor blade and potential flow regions on outer field where free vortex methods are used to model the vortical flowfield [10-12].

BEM methods although based on a "two-dimensional" theory provide acceptable approximations to the axisymmetric distribution of inflow and loads found under conditions where the wind is normal to the plane of the rotor (i.e., the turbine is in zero yaw angle with respect to the oncoming wind), and there are no dynamic stall effects [13]. This explains their use in the preliminary studies concerning the performance of horizontal axis wind turbine (HAWT) rotors. A full aerodynamic analysis however should take into account important operational parameters like wind turbulence and shear. This can be accomplished with the full Navier-Stokes solvers. This class of methods has the potential to provide a consistent and physically realistic simulation of the turbine flow field. The field of CFD applied to rotating-blade problems is reviewed by McCroskey [14], Landgrebe [15], Hansen et al. [16] and Hu et al. [17].

The aim of the present work is to perform a 3-D flow analysis of a three-bladed small-sized rotor from the Viscous and Aeroelastic Effects on Wind Turbine Blades - Phase II (VISCEL-II) project [18] with the aid of a commercially available CFD package. Several 2-D and 3-D simulations were carried out to yield information on different aspects involved, ranging from aerodynamic calculations to wake development. The calculations are compared with experimental data for validation purposes. 


\section{TURBINE GEOMETRY}

The National Renewable Energy Laboratory (NREL) phase-II rotor mounted on a downwind machine is a small three bladed HAWT rotor with $5.029 \mathrm{~m}$ radius [19], as shown in Fig. (1). The blades of the phase-II rotor are non-twisted and non-tapered with a constant cord of $0.4572 \mathrm{~m}$. The NREL S809 airfoil series is used, except for the root. At $14.4 \%$ span the airfoil thickness is $\mathrm{t} / \mathrm{c}=43 \%$ and decreases linearly to $t / c=20.95 \%$ at $30 \%$ span, while outboard of $30 \%$, thickness is constant at that value. The nominal rotation speed is $71.68 \mathrm{rpm}$ and the pitch is $12 \mathrm{deg}$. This HAWT rotor was chosen to use data from the NREL phase-II experiment as reported in 'IEA Annex XIV:Field Rotor Aerodynamics' [18] where also the geometry of the rotor is thoroughly described.

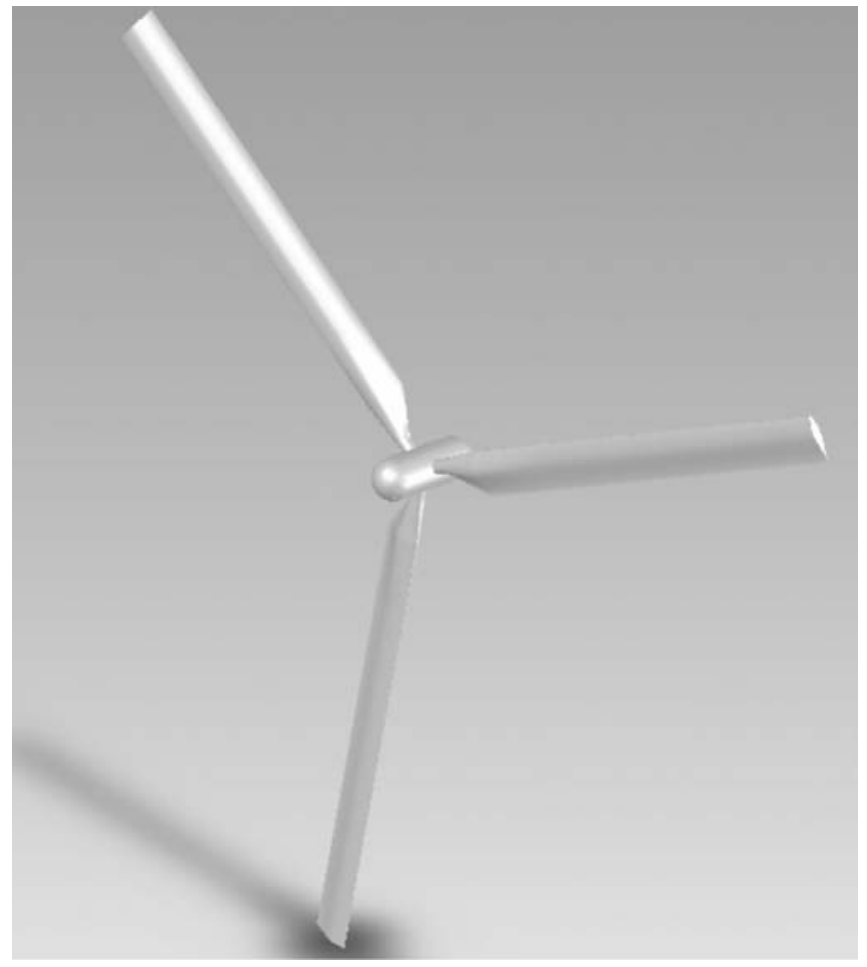

Fig. (1). Different views of the NREL Phase II Rotor.

\section{DESCRIPTION OF THE N-S SOLVER}

The physico-mathematical modeling of the complicated HAWT rotor flow is provided by the steady, incompressible, isothermal Reynolds Averaged Navier-Stokes (RANS) equations [20, 21], i.e.

$\nabla\left(\mathrm{u}_{\mathrm{i}}\right)=0$

$\rho \frac{\partial}{\partial x_{j}}\left(\bar{u}_{i} \bar{u}_{j}\right)=-\frac{\partial \bar{p}}{\partial x i}+\frac{\partial}{\partial x_{j}}\left(\bar{\tau}_{i j}-\overline{\rho u_{i} u_{j}}\right)$

combined with one of the existing options for turbulence modeling. The one-equation Spalart-Allmaras model [22, 23] with standard wall functions $\left(\mathrm{y}^{+} \geq 30\right)$ is proposed due to its efficiency in combining accuracy with low computing cost.

$$
\begin{aligned}
& \frac{\partial}{\partial t}(\rho \bar{v})+\frac{\partial}{\partial x_{i}}\left(\rho \bar{v} u_{i}\right)= \\
& G_{v}+\frac{1}{\sigma_{\bar{v}}}\left\{\frac{\partial}{\partial x_{j}}\left[(\mu+\rho \bar{v}) \frac{\partial \bar{v}}{\partial x_{j}}\right]+C_{b 2} \rho\left(\frac{\partial \bar{v}}{\partial x_{j}}\right)^{2}\right\}-Y_{v}+S_{\bar{v}}
\end{aligned}
$$

where $G_{v}$ is the production of turbulent viscosity, $Y_{v}$ is the destruction of turbulent viscosity that occurs in the near-wall region due to wall blocking and viscous damping, $v$ is the molecular kinematic viscosity, $\tilde{v}$ is identical to the turbulent kinematic viscosity except in the near-wall region, $\sigma_{\tilde{v}}$ and $\mathrm{C}_{\mathrm{b} 2}$ are constants and $\mathrm{S}_{\tilde{v}}$ is a user defined source term.

The transport variable $\tilde{v}$ is related to the turbulent viscosity as follows

$\mu_{\mathrm{t}}=\rho \tilde{v} f_{u}$

The viscous damping function $f_{u}$ is given by

$$
\mathrm{f}_{\mathrm{u}}=\frac{\chi^{3}}{\chi^{3}+\mathrm{C}_{\mathrm{u}}^{3}}
$$

where $\chi$ relates the molecular velocity and the transport variable and is defined by the following equation

$\chi \equiv \frac{\tilde{v}}{v}$

The equations are solved by the commercial code Fluent [21] using the single reference frame (SRF) technique attached to the blades of the rotor. The non-linear system of equations implies the segregated solver, thus is solved sequentially. PRESTO and QUICK discretization schemes are used for the continuity and the momentum equations respectively. The PRESTO scheme [24] uses the discrete continuity balance for a "staggered" control volume about the face to compute the "staggered" pressure. QUICK-type schemes [25] are based on a weighted average of secondorder-upwind and central interpolations of the variable. As the code solves the incompressible flow equations, no equation of state exist for the pressure, and the SIMPLE algorithm is used to enforce pressure-velocity coupling.

\section{COMPUTATIONAL DOMAIN AND GRID}

In the current research work, the wind turbine tower and the ground are neglected, which is a fair approximation for HAWT rotor simulation. The computational domain is enclosed between a small inner cylinder and an outer cylinder with diameter equal to 6 times the rotor diameter, both axial centered. Thus, the region, which includes the hub of the rotor, is completely removed from the domain. The field is extended to 8 rotor diameters downwind of the turbine and 2 diameters upwind. Exploiting the 120 degrees periodicity of the three-bladed rotor, only one of the blades is explicitly modeled using the SRF technique as shown in Fig. (2). 


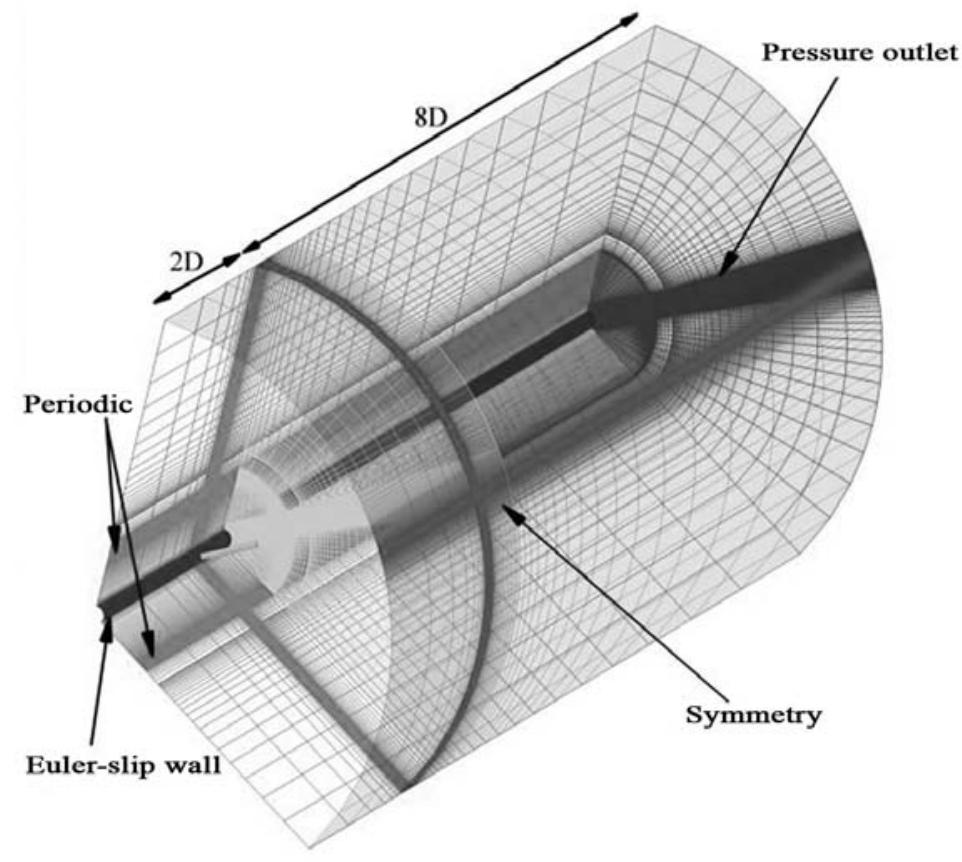

Fig. (2). The control volume meshing in 120 degrees section and definition of the boundary conditions.

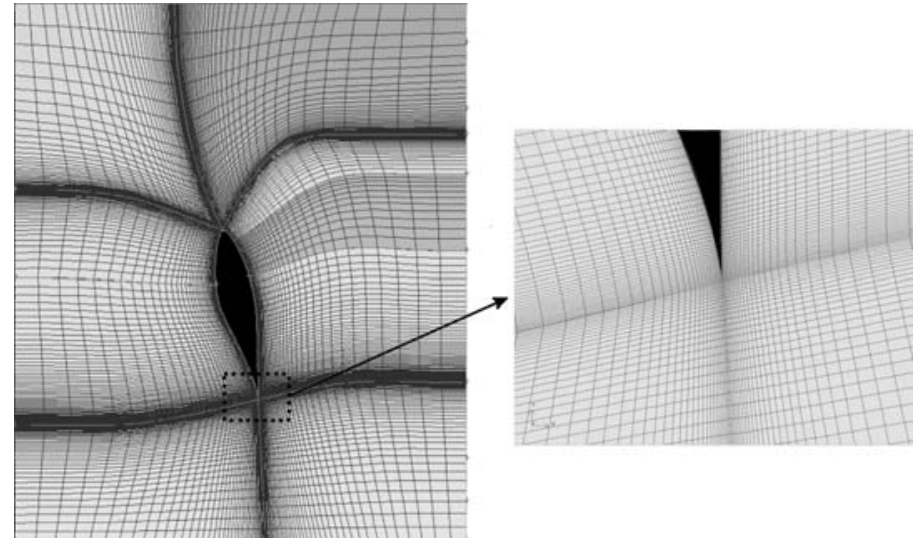

Fig. (3). Mesh construction around the blade of the rotor. Left picture shows the mesh around the blade and the right picture shows detail of the mesh near the trailing edge of the blade.

The Fluent's pre-processor Gambit is used to create the volume mesh. It is a hexahedral mesh of approximately 3.3 million cells $(145 \times 135 \times 167$ cells in $\mathrm{x}, \mathrm{r}$ and $\vartheta$ directions respectively). As shown in Fig. (3), the grid around the blade is H-type which is optimized to resolve the boundary layer for standard wall functions $\left(\mathrm{y}^{+} \geq 30\right)$. All the calculations were carried out in an Intel Core 2 quad Extreme QX6800 with $8 \mathrm{~Gb}$ Ram. The number of iterations adjusted to reduce the scaled residual below the value of $10^{-5}$ which is the criterion of convergence. For each run, the observation of the static pressure, at a specific point in the free-stream behind the rotor and the value of the rotor power were appointed for the convergence of the solution. Aiming to smooth convergence, various runs were attempted by varying under-relaxations factors. In that way, a direct control regarding the update of computed variables through iterations, was achieved. Initializing with low values for the first iterations steps and observing the progress of the residuals, their values were modified for accelerating the convergence. For a typical run of a case the cpu time was approximately 20 days and the construction time of the domain grid was about a month. This is a factor that does not permit a grid independence task procedure.

The working fluid for this analysis is the air with density equal to the reference value in the experimental data which is $0.997 \mathrm{~kg} / \mathrm{m}^{3}$ [18]. A uniform wind speed profile of $7.2 \mathrm{~m} / \mathrm{s}$ is assumed at the entrance of the domain as boundary condition with fixed turbulence intensity and turbulence viscosity ratio. The nominal rotation speed is $71.68 \mathrm{rpm}$. The boundary condition for the inner cylinder is Euler-slip and for the outer one is symmetry, as shown in Fig. (2). The no-slip wall condition is assigned to the rotor blade surface and the pressure outlet condition to the downwind extreme of the field.

\section{RESULTS}

The commercial CFD code Fluent [21] is used for all the calculations presented. In order to validate the numerical results, experimental data are used from the 'IEA Annex 


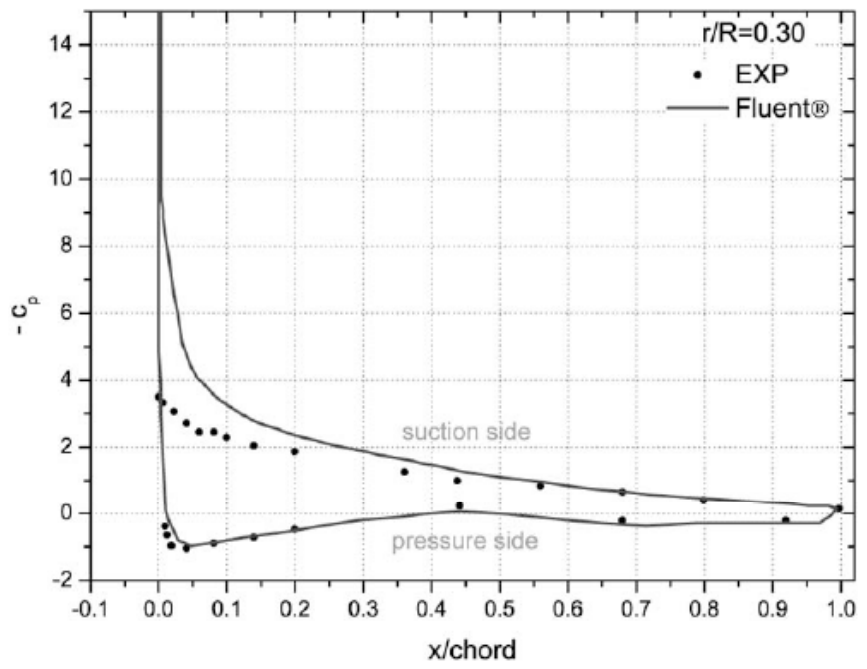

Fig. (4a). Computed and experimental "EXP" [19] chord-wise pressure distributions at $\mathrm{r} / \mathrm{R}=0.30$ span-wise location.

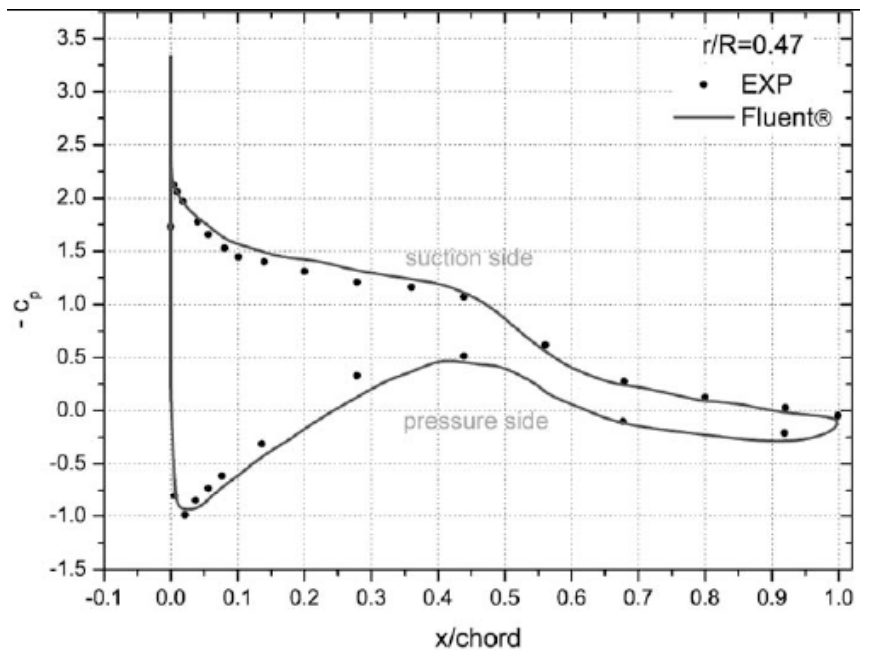

Fig. (4b). Computed and experimental "EXP" [19] chord-wise pressure distributions at $\mathrm{r} / \mathrm{R}=0.47$ span-wise location.

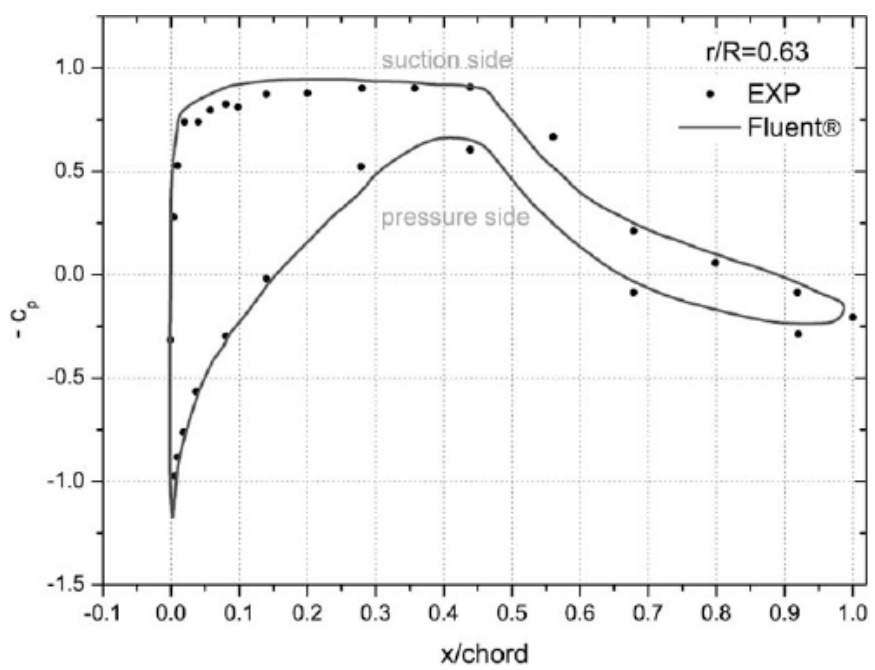

Fig. (4c). Computed and experimental "EXP" [19] chord-wise pressure distributions at $\mathrm{r} / \mathrm{R}=0.63$ span-wise location.

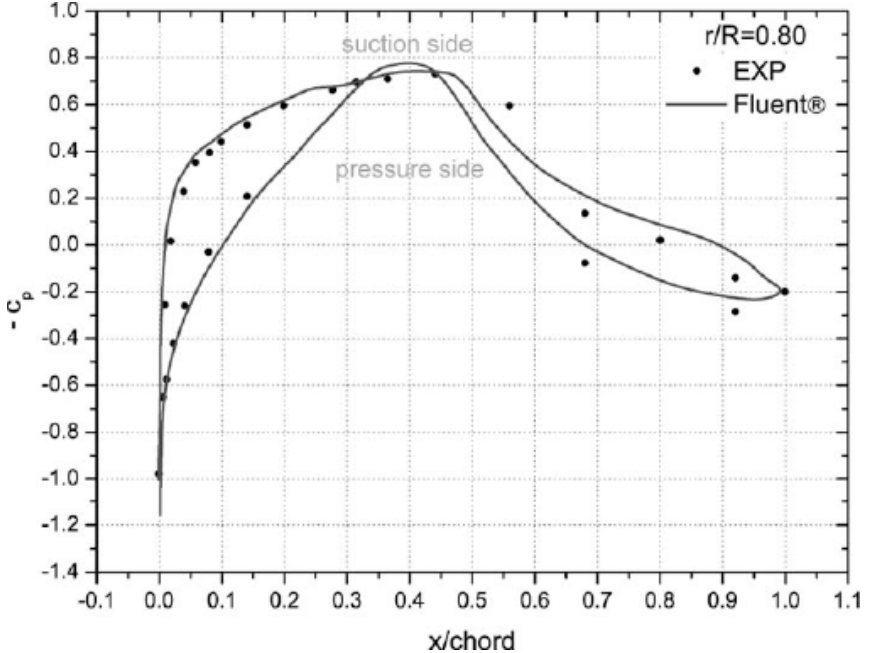

Fig. (4d). Computed and experimental "EXP" [19] chord-wise pressure distributions at $\mathrm{r} / \mathrm{R}=0.80$ span-wise location.

XIV: Field Rotor Aerodynamics' report [19]. In Figs. (4a, $\mathbf{4 b}, \mathbf{4 c}$ and $\mathbf{4 d}$ ), the numerical pressure coefficient distribution is presented and compared with experimental results for $30,47,63$ and $80 \%$ spanwise locations, respectively. The calculated pressure coefficient follows the definition applied in experimental data for reasons of direct comparison. Therefore, the pressure coefficient is:

$c_{p}=\frac{\left(p-p_{\text {hub }}\right)+p_{\text {cent }}}{q_{\text {ref }}^{2}}$

where $\mathrm{p}$ is the local pressure on the blade surface, $\mathrm{p}_{\text {hub }}$ is the reference pressure on the hub of the rotor, $\mathrm{p}_{\text {cent }}=0.5 \rho(\Omega r)^{2}$ is the static pressure that accounts the centrifugal action of the flow and $\mathrm{q}_{\mathrm{ref}}$ is the reference dynamic pressure in a distance of about half chord upstream of the blade in the corresponding radial position.

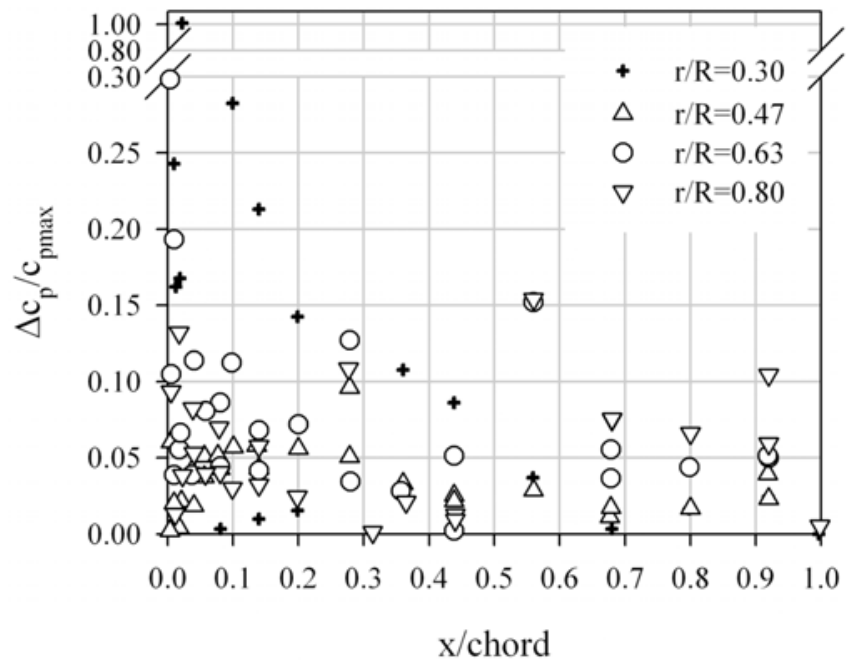

Fig. (5). Deviation of the computed pressure coefficients from the corresponding experimental in the four sections examined alongside blade.

To minimize the influence of the tower on the experimental results instantaneous data at an azimuthal blade positions of $90 \mathrm{deg}$ are used, i.e. when the blade is horizontal 


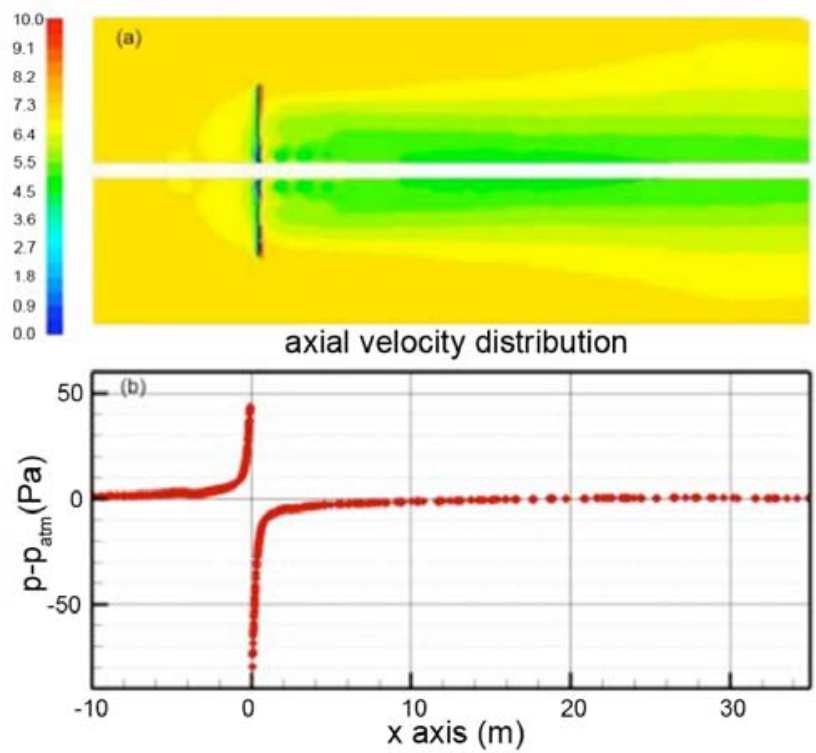

Fig. (6). Near wake axial velocity distributions (a) and pressure distribution (b) along longitudinal axis of the NREL Phase II rotor at hub height.

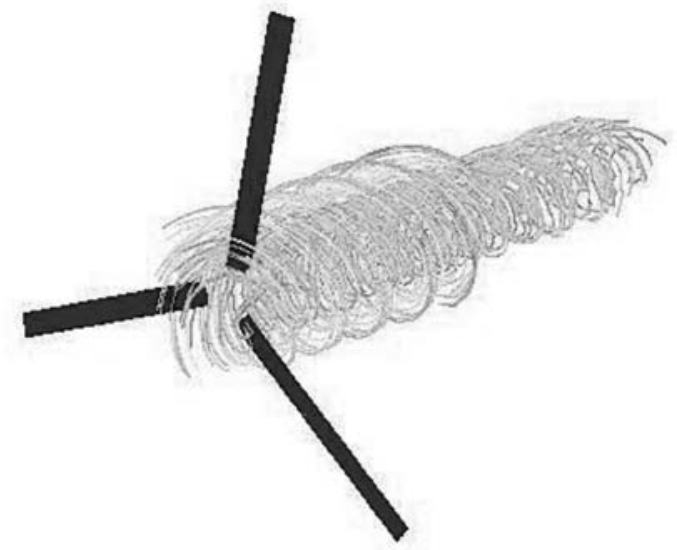

Fig. (7). Pathlines at blade root.

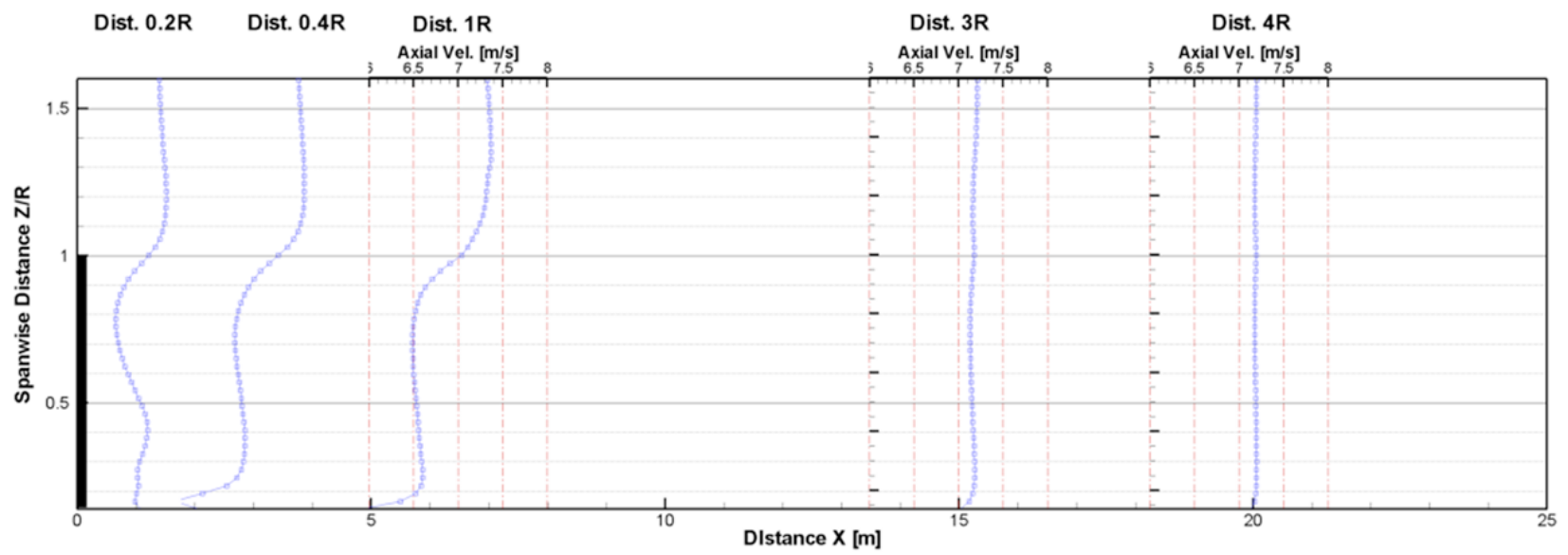

Fig. (8). Axial velocity distribution at various stations alongside free stream.

and moving down towards the tower. The comparison between the calculated pressure distribution and the experimental data is in satisfactory agreement. Some inaccuracies occur on the leading edge of the blade section and seem to increase at span-wise positions closer to the rotor hub.
The accuracy of the computed pressure coefficients against the corresponding experimental values are verified in terms of their percentage deviation at the four spanwise examined stations, as shown in Fig. (5). The majority of the deviations are less than $6 \%$. However, some important discrepancies are observed in the $r / R=0.30$ station near the 
blade root. The above observed discrepancies are probably due to the highly separated flow region which is not properly resolved with the RANS approximation.

The evolution of the produced wake from the rotor blade is depicted in the axial velocity contour plot which is shown in Fig. (6a). As expected, the cone shape of the wake evolution downward the rotor is clearly shown. Strong tip vortices are not clearly visible in this plot. However, in Fig. $(\mathbf{6 b})$, the relative to atmospheric static pressure variation along the longitudinal dimension of the field, it can be observed. The pressure increases gradually, approaching the rotor blade where a deep drop occurs, as expected, and after 1.5 rotor diameters downwind the pressure gradients diminish. The pressure rises before the rotor is in agreement with the theory, while the sudden pressure drop gradient is associated with the power extraction of the wind.

Theoretically, behind a HAWT rotor the generated wake central vortices developed near the blade root. This is represented in the latter contour plot and at the pathlines of Fig. (7), where the relative flowfield is shown near the blade root with strong three dimensional effects.

The development of the limiting streamlines (i.e. the curves whose directions coincide with that of the vanishing fluid velocity or the shear stress, at the surface) for both blade sides is shown in Fig. (9). It is clear that near the root, strong 3D effects occur and the flow separates. The effect of rotation, which becomes more pronounced at inboard locations of the blade, is to suppress vortex shedding and the development of separation bubbles. When the flow separates, the Coriolis force acts as a favorable pressure gradient, causing the reattachment of the flow, and the reduction in the separation bubble volume. The reduction of

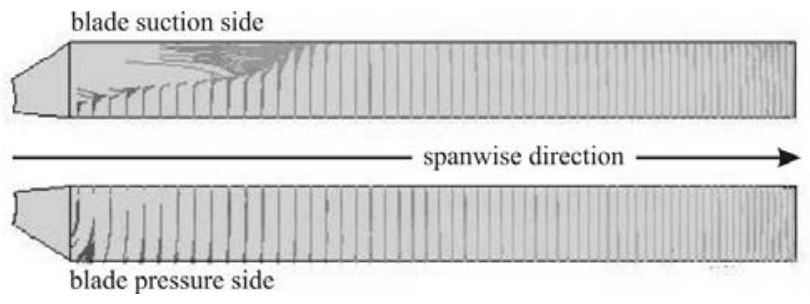

Fig. (9). Development of the limiting streamlines for the NREL Viscel II rotor blade.

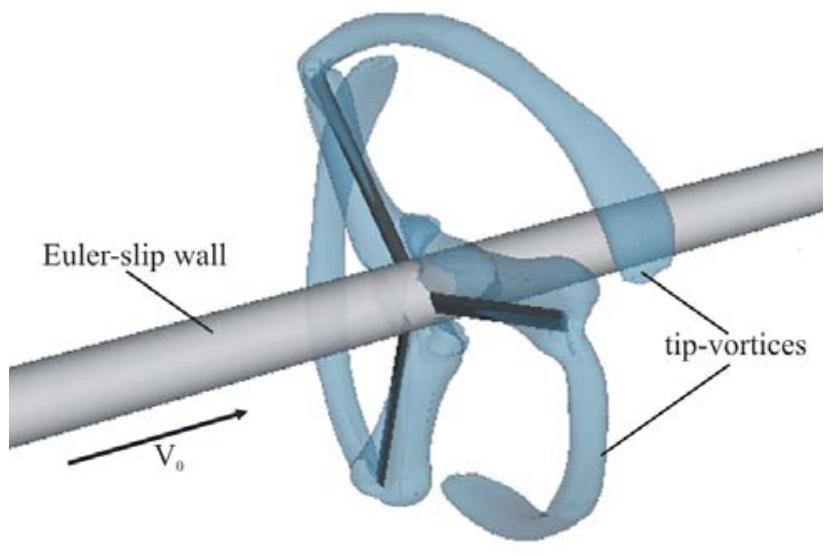

Fig. (10). Vorticity iso-surface $\left(\mathrm{U}_{0}=7.2 \mathrm{~m} / \mathrm{s}\right)$. the bubble volume produces a pressure drop along the suction side of the airfoils increasing, thus, the blade loading.

The axial velocity distributions in the wake are observed in the axial velocity contour plots of the Figs. (11) and (8). It can be noticed that outside the wake shape downwind of the rotor, the axial velocity attains the free stream value. The deviation of the axial velocities from the free stream values is noticeable, rotor is further amplified after the upwind. Vortices are shed from the trailing edges of the blades which are diffusing in the far wake. These contours are used to identify the transition from the near to the far wake. In the near wake the shed vortices appear as distinct vortex spiral tubes as shown in Fig. (10). The involved vorticity strength decays in the downstream direction following the theoretical signature for such vorticity field structure.

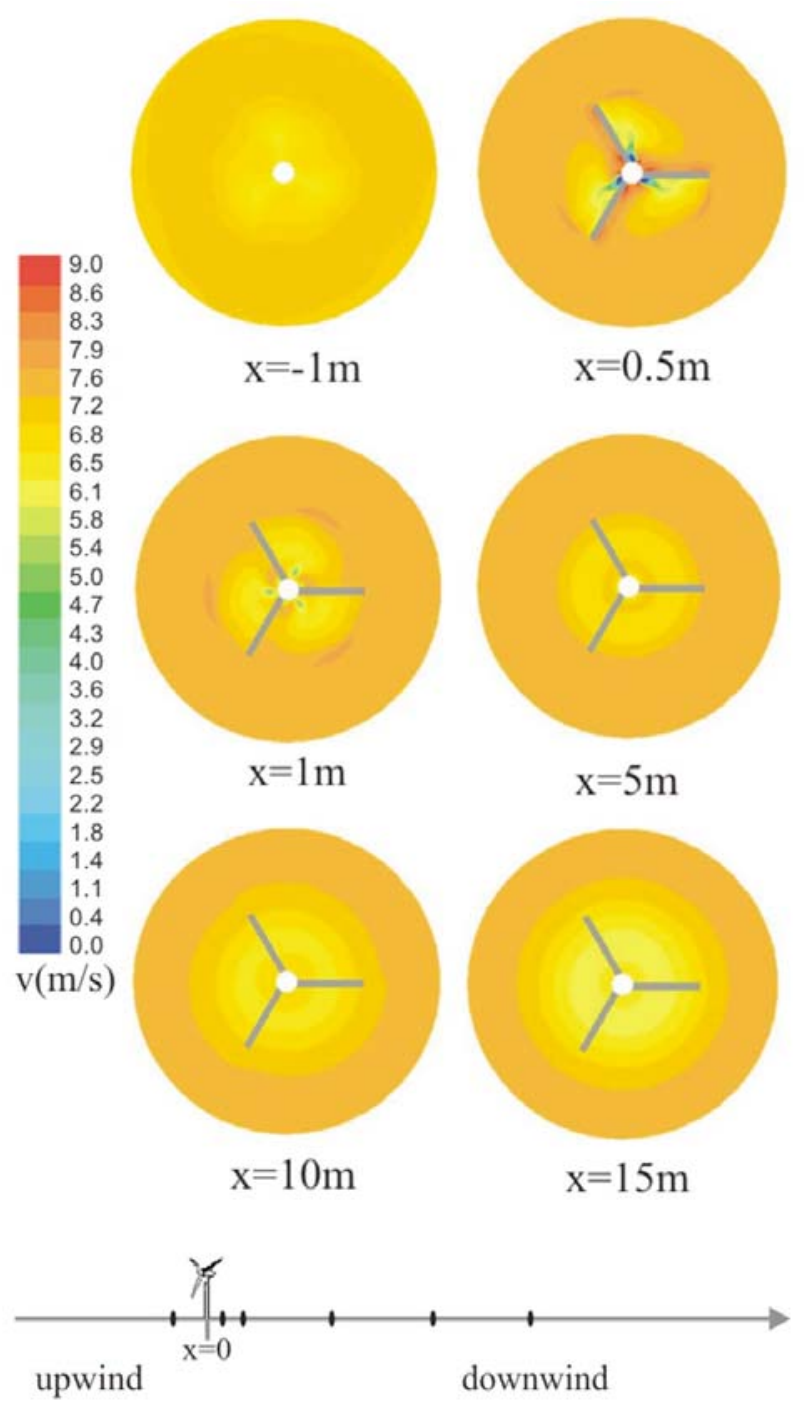

Fig. (11). Calculation of the axial velocity contours at different positions upwind and downwind of the NREL Phase II rotor.

\section{CONCLUSIONS}

The aerodynamic characteristics of a model HAWT are predicted by means of the commercial CFD code Fluent. Despite the evident simplicity of the wind turbine flowfield, 
there are three-dimensional effects, separated flows, wakes interactions and vortices which transform it to a complicated one.

The purpose of the current work is the numerical study on aerodynamic behavior of HAWT rotor and the validation of the simulation with available experimental data. The numerical simulations also allow the prediction of the basic features of the wake development downwind the rotor. Different aspects of HAWT flowfield are resolved with good accuracy, despite the different relevant scales involved. The simulations were validated and assessed against detailed wind turbine aerodynamic data. Nevertheless, the code and turbulence models failed to predict experimental power curves and further research is needed in that direction.

The study confirms that RANS simulations are capable to solve with a fair accuracy the different aspects involved in HAWT flowfield, thus this confirms that nowadays CFD simulations can be the most important tool for analysis and design of wind turbine rotors.

Finally, one of the future research directions will be the CFD simulation of the wind turbine flowfield with the detached-eddy simulation (DES) approach in order to better understand and fully simulate the complicated 3-d phenomena produced.

\section{NOMENCLATURE}

$$
\begin{aligned}
& \mathrm{c}_{\mathrm{p}} \quad=\text { Pressure coefficient [dimensionless] } \\
& \mathrm{G}_{v}=\text { Production of turbulent viscosity } \\
& \mathrm{p} \quad=\text { Pressure }[\mathrm{Pa}] \\
& \mathrm{p}_{\mathrm{atm}}=\text { Atmospheric pressure }[\mathrm{Pa}] \\
& \mathrm{R}=\text { Radius of the wind turbine rotor }[\mathrm{m}] \\
& \mathrm{SRF}=\text { Single Reference Frame technique } \\
& \mathrm{t}=\text { Time }[\mathrm{s}] \\
& \mathrm{u}_{\mathrm{i}}=\text { Overall velocity component }[\mathrm{m} / \mathrm{s}] \\
& \mathrm{U}_{0}=\text { Free-stream velocity }[\mathrm{m} / \mathrm{s}] \\
& \mathrm{y}^{+}=\text {Dimensionless wall distance } \\
& Y_{v}=\text { Destruction of turbulent viscosity }
\end{aligned}
$$

\section{GREEK LETTERS}

$$
\begin{aligned}
\mu_{\mathrm{t}} & =\text { Turbulent viscosity }\left[\mathrm{m}^{2} / \mathrm{s}\right] \\
v & =\text { Molecular kinematic viscosity }\left[\mathrm{m}^{2} / \mathrm{s}\right] \\
\tilde{v} & =\text { Turbulent kinematic viscosity }\left[\mathrm{m}^{2} / \mathrm{s}\right] \\
\rho & =\text { Density }\left[\mathrm{kg} / \mathrm{m}^{3}\right]
\end{aligned}
$$

\section{REFERENCES}

[1] Executive Committee for International Energy Agency, Wind Energy, IEA Annual Report 2004, 2005.
[2] R.E. Wilson and P.B.S. Lissaman, "Applied aerodynamics of wind power machines", NTIS PB 2385594, Oregon State University, 1974

[3] F.J. Simoes and J.M.R. Graham, "A free vortex model of the wake of a horizontal axis wind turbine", 12th British Wind Energy Association Conference, 1990, pp. 161-165.

[4] N.S. Tachos, A.P. Fragias, E.G. Fenekos, D.P. Margaris and D.G. Papanikas, "Aerodynamic noise prediction of a horizontal axis wind turbine rotor", Special Topic Conference, The Science of making Torque from Wind, EWEA, 2004, pp. 273-281.

[5] N.N. Sørensen and M.O.L. Hansen, "Rotor performance predictions using a Navier-Stokes method. In: ASME Wind Energy Symposium, 36th AIAA Aerospace Sciences Meeting and Exhibit, AIAA-98-0025, Reno, NV, 1998.

[6] G. Xu and L.N. Sankar, "Computational study of horizontal axis wind turbines", ASME Wind Energy Symposium, 37th AIAA Aerospace Sciences Meeting and Exhibit, AIAA-99-0042, Reno, NV, 1999.

[7] J.N. Sørensen and W.Z. Shen, "Numerical modelling of wind turbine wakes", J. Fluids Eng., vol. 124, pp. 393-399, 2002.

[8] N.N. Sørensen, "3-D background aerodynamics using CFD”, Ris $\emptyset$ R-1376, Ris $\varnothing$ National Laboratory, Denmark, 2002.

[9] N.N. Sørensen, J. Johansen and S. Conway, "CFD computations of wind turbines blade loads during standstill operation", Know-Blade Task-3.1 Report, Risø-R-1465(EN), Risø National Laboratory, Denmark, 2004.

[10] G. Xu and L.N. Sankar, "Effects of transition, turbulence and yaw on the performance of HAWT", 38th AIAA Aerospace Sciences Meeting and Exhibit, January 10-13, Paper 2000-0048, Collection of Technical Papers (A00-16885 03-44), Reno, NV, 2000.

[11] S. Benjanirat, L.N. Sankar and G. Xu, "Evaluation of turbulence models for the prediction of wind turbine aerodynamics", Wind Energy Symp., AIAA Paper 2003-0517, Reno, NV, 2003.

[12] G. Xu and L.N. Sankar, "Application of a viscous flow methodology to the NREL phase VI rotor", Proceedings of the 21st ASME Wind Energy Conference and the 40th AIAA Aerospace Sciences Meeting, Paper 2002-0030, Reno, NV, Jan. 14-17, 2002, pp. 83-93.

[13] J.L. Tangler, "The nebulous art of using wind tunnel airfoil data and blade-element momentum theory for predicting rotor performance", 21st ASME Wind Energy Symposium and the 40th AIAA Aerospace Sciences Meeting, Paper 2002-0040, Reno, NV, Jan. 1417, 2002.

[14] W.J. McCroskey, "Vortex wakes of rotorcraft", 33rd AIAA Aerospace Sciences Meeting and Exhibit, Paper 95-0530, Reno, NV, Jan. 9-12, 1995.

[15] A.J. Landgrebe, "New directions in rotorcraft computational aerodynamics research in the U.S.", In: AGARD, Aerodynamics and Aeroacoustics of Rotorcraft, AGARD CP-552, Berlin, 1994.

[16] M.O.L. Hansen, J.N. Sørensen, S. Voutsinas, N. Sørensen and H.A Madsen, "State of the art in wind turbine aerodynamics and aeroelasticity", Progress in Aerospace Sciences, 42, pp. 285-330, 2006

[17] D. Hu, O. Hua and Z. Du, "A study on stall-delay for horizontal axis wind turbine", Renewable Energy, 31, pp. 821-836, 2006.

[18] J.G. Schepers, A.J. Brand, A. Bruining, J.M.R. Graham, M.M. Hand, D.G. Infield, H.A. Madsen, R.J.H. Paynter and D.A. Simms, "Final report of IEA Annex XIV: field rotor aerodynamics", ECNC-97-027, Energy Research Center of the Netherlands, 1997.

[19] D. Simms, S. Schreck, M. Hand and L. Fingersh, "NREL Unsteady Aerodynamics Experiment in the NASA-Ames Wind Tunnel: A Comparison of Predictions to Measurements", National Renewable Energy Laboratory, NREL/TP-500-29494, 2001.

[20] J.C. Tannehill, D.A. Anderson and RH. Pletcher, "Computational Mechanics and Heat Transfer". Taylor \& Francis Inc., NY, 2nd ed., 1997.

[21] Fluent Inc., Fluent 6.2 Documentation-User's Guide, 2004.

[22] P.R. Spalart and S.R. Allmaras, "A one-equation turbulence model for aerodynamic flows", Technical Report AIAA-92-0439, American Institute of Aeronautics and Astronautics, 1992.

[23] D.C Wilcox, "Turbulence modelling for CFD". DCW Industries Inc., 2nd ed., 1998. 
[24] S.V. Patankar, "Numerical Heat Transfer and Fluid Flow". Hemisphere, Washington, DC, 1980.
[25] B.P. Leonard and S. Mokhtari, "Nonoscillatory Convection Schemes for High-Speed Steady Multidimensional Flow", NASA TM 1-2568 (ICOMP-90-12), NASA Lewis Research Center, 1990.

Received: March 30, 2008

(C) Tachos et al.; Licensee Bentham Open.

This is an open access article licensed under the terms of the Creative Commons Attribution Non-Commercial License (http://creativecommons.org/licenses/bync/3.0/), which permits unrestricted, non-commercial use, distribution and reproduction in any medium, provided the work is properly cited. 